\title{
Threshold Model of Singapore and U.K. Stock Return Volatility in South-east Asia Markets: Study of the Thailand and the Malaysian's Stock Markets
}

\author{
Horng Wann-Jyi ${ }^{1}$ Chen Ching-Huei ${ }^{2}$ Hsu Liu-Hsiang ${ }^{3}$ \\ ${ }^{1}$ Department of Hospital and Health Care Administration, Chia Nan University of Pharmacy \& Science, No. 60, Erh-Jen \\ Rd., Sec.1, Jen-Te, Tainan, 71710, Taiwan. E-mail: hwj7902@mail.chna.edu.tw \\ 2 Department of Hospital and Health Care Administration, Chia Nan University of Pharmacy \& Science, No. 60, Erh-Jen \\ Rd., Sec.1, Jen-Te, Tainan, 71710, Taiwan. E-mail: wilsonchen0831@yahoo.com.tw \\ ${ }^{3}$ Department of Business Administration, Ling Tung University, No. 1, Ling Tung Rd., Taichung, 40852, Taiwan. \\ E-mail: lucian@teamail.ltu.edu.tw
}

\begin{abstract}
The empirical results show that the dynamic conditional correlation (DCC) and the bivariate $\operatorname{AIGARCH}(1,1)$ model is appropriate in evaluating the relationship of the Thailand's and the Malaysian's stock markets. The empirical result also indicates that the Thailand's and the Malaysian's stock markets is a positive relation. The average estimation value of correlation coefficient equals to 0.424 , which implies that the two stock markets is synchronized influence. Besides, the empirical result also shows that the Thailand's and the Malaysian's stock markets have an asymmetrical effect. The return volatility of the Thailand and the Malaysian stock markets receives the influence of the good and bad news of the Singapore and the U.K. stock return volatility rates.
\end{abstract}

Keywords: Stock market returns, asymmetric effect, IGARCH model, AIGARCH model.

\section{Introduction}

We know that Thailand's economical physique belongs partly to an island economy. We also know that Thailand is the major economical financial system in the Association of South-east Asia Nations. We also know that Malaysian is also one of Association of South-east Asian Nations. Based on the Growth Competitiveness Index Rankings in 2003-2004 (it is published in the World Economic Forum), the rank of Malaysia is 29 in the world. Another, also based on the World Competitiveness Yearbook in 2006, the rank of Malaysia is 23 in the world competitiveness. When the investor has an investment in the international stock market, he/she will usually care about the international capital the motion situation, the international politics and the economical situation change, in particular, in the Singapore and the U.K. stock markets' changes. Thailand and Malaysian have also a close relationship for the geographic position based on the trade and the circulation of capital with the Singapore and the U.K. And we also know that the Singapore and the U.K. are also powerful global economical nations. Therefore, the relationship between the Thailand and the Malaysian stock markets is worth further discussion with the factors of the Singapore and U.K. stock markets.

The purpose of the present paper is to examine the relations of the Thailand's and the Malaysian's stock markets. This paper also further discusses the affect of the Singapore and the U.K. stock returns' volatility for the Thailand and the Malaysian stock market return rates. And the positive and negative values of Singapore and U.K. stock returns' volatility are used as the threshold. The organization of this paper is as follows: Section 2 descibes the data characteristics; Section 3 presents the proposed model; Section 4 presents the empirical results; Section 5 introduces the asymmetric test of the proposed model, and finally Section 6 summarizes the conclusions of this study.

\section{Data characteristics}

\subsection{Data sources}

The data of this research included the Thailand, the Malaysian, the Singapore and the U.K. stock price collected between January, 2004 and December, 2011. The source of the stock data was the Taiwan economic Journal (TEJ), a database in Taiwan. The Thailand's stock price refers to the Bangkok set stock index, the Malaysian's stock price refers to the Kuala Lumpur stock index, the Singapore's stock price refers to Strait Times stock index, and the U.K. stock price refers to the London FTSE100 stock index. During the process of data analysis, in case that there was no stock market price available on the side of the Thailand and the Malaysian stock markets or on the side of the Singapore and the U.K. stock markets due to holidays, the identical time stock price data from one side was deleted. After this, the four variables samples are 1,968 


\subsection{Returns Calculation and Basic Statistics}

To compute the return volatility of the Thailand stock market adopts the natural logarithm difference, rides 100 again. The return volatility of the Malaysian stock market also adopts the natural logarithm difference, rides 100 again. The return volatility of the Singapore and the U.K. stock markets also adopts the natural logarithm difference, rides 100 again. In Figure 1, the Thailand, the Malaysian, the Singapore and the U.K. stock return rate volatility shows the clustering phenomenon, so that we may know the four stock markets have certain relevance.

Table 1 presents the four sequences kurtosis coefficients are all bigger than 3 , which this result implies that the normal distribution test of Jarque-Bera is not normal distribution. Therefore, the heavy tails distribution is used in this paper. And the four stock markets do have the high correlation in Table 2.
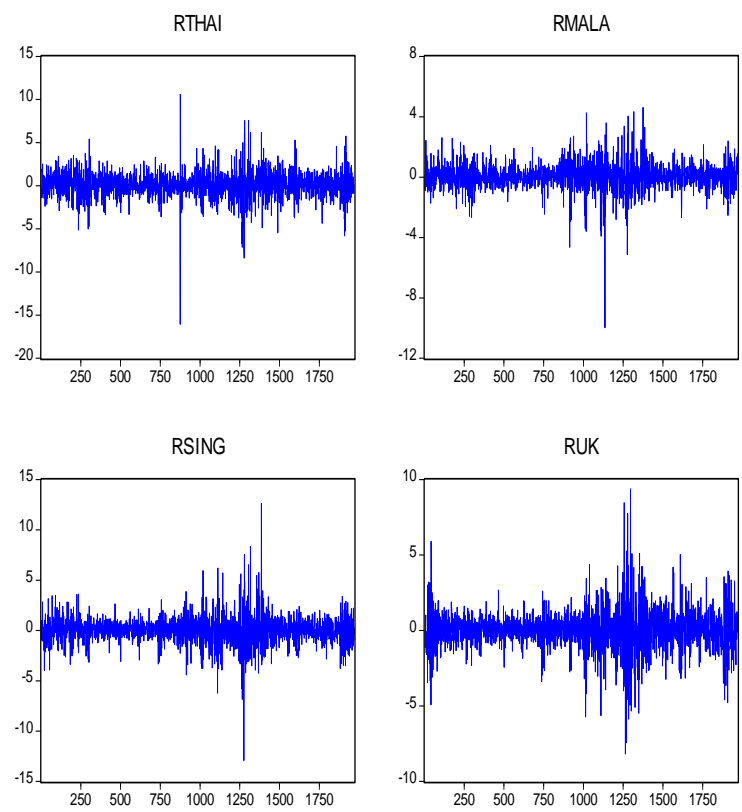

Figure 1. Trend charts of the Thailand, the Malaysian, the Singapore and the U.K. stock market volatility rates.

Table 1. Data statistics

\begin{tabular}{|c|c|c|c|c|}
\hline Statistics & RTHAI & RMALA & RSING & RUK \\
\hline Mean & 0.0544 & 0.0449 & 0.0347 & 0.0167 \\
\hline S-D & 1.5213 & 0.8860 & 1.3709 & 1.3217 \\
\hline Skew & -0.5523 & -0.8379 & 0.0775 & -0.0002 \\
\hline Kurtosis & 12.7021 & 14.3971 & 13.6377 & 9.1063 \\
\hline J-B N & $7814.9^{* * *}$ & $\begin{array}{c}10876.1 \\
\text { (p-v** }\end{array}$ & $\begin{array}{c}9276.4^{* * *} \\
(0.0000)\end{array}$ & $\begin{array}{c}3056.0 \\
(0.0000)\end{array}$ \\
$(0.0000)$ \\
\hline Sample & 1967 & 1967 & 1967 & 1967 \\
\hline
\end{tabular}

Notes: (1) J-B N is the normal distribution test of Jarque-Bera.
(2) S-D is denoted the standard deviation. (3) ${ }^{* * *}$ denote significance at the level $1 \%$.

Table 2. Unconditional correlation coefficient

\begin{tabular}{|c|c|c|c|c|}
\hline Coefficient & THAI & MALA & SING & UK \\
\hline THAI & 1 & 0.845 & 0.765 & 0.691 \\
\hline MALA & 0.845 & 1 & 0.889 & 0.694 \\
\hline SING & 0.765 & 0.889 & 1 & 0.909 \\
\hline UK & 0.691 & 0.694 & 0.909 & 1 \\
\hline
\end{tabular}

\subsection{Unit root and co-integration tests}

This paper further uses the unit root test of KSS [1] to determine the stability of the time series data. The KSS examination result is listed in Table 3. Table 3, it shows that the return volatility of those four stock markets do not have the unit root characteristic, this is, those four stock markets are stationary series data, under $\alpha=1 \%$ significance level.

Using Johansen's [2] co-integration test as illustrated in Table 4 at the significance level of $0.05(\alpha=5 \%)$ does not reveal of $\lambda_{\max }$ statistic. This indicated that the Thailand, the Malaysian, the Singapore and the U.K. stock markets do not have a co-integration relation. Therefore, we do not need to consider the model of error correction.

\subsection{ARCH effect test}

Based on the formula (1) and (2) as below, we uses the methods of LM test [3] and F test [4] to test the conditionally heteroskedasticity phenomenon. In Table 5, the results of the ARCH effect test show that the two markets do have the conditionally heteroskedasticity phenomenon exists with the factors of the Singapore and the U.K. stock markets. This result suggests that we can use the GARCH model to match and analyze it.

Table 3. Unit root test of KSS for the return data

\begin{tabular}{|c|c|c|c|c|}
\hline KSS & RTHAI & RMALA & RSING & RUK \\
\hline Statistic & $-20.084^{* * *}$ & $-16.603^{* * *}$ & $-16.975^{* * *}$ & $-20.443^{* * *}$ \\
\hline $\begin{array}{c}\text { Critical } \\
\text { value }\end{array}$ & -2.82 & -2.22 & -1.92 & \\
\hline $\begin{array}{c}\text { Significant } \\
\text { level }\end{array}$ & $\alpha=1 \%$ & $\alpha=5 \%$ & $\alpha=10 \%$ & \\
\hline
\end{tabular}

Notes: ${ }^{* * *}$ denote significance at the level $1 \%$.

Table 4. Co-integration test ( VAR LAG=2)

\begin{tabular}{|c|c|c|}
\hline$H_{0}$ & $\lambda_{\max }$ & Critical value \\
\hline None & 25.907 & 30.815 \\
\hline At most 1 & 11.685 & 24.252 \\
\hline At most 2 & 4.482 & 17.148 \\
\hline At most 3 & 1.896 & 3.842 \\
\hline
\end{tabular}

Notes: The lag of VAR is selected by the AIC rule [5].

The critical value is given under the level 5\%. 
Table 5. ARCH effect test

\begin{tabular}{|c|c|c|}
\hline RTHAI & Engle LM test & Tsay F test \\
\hline Statistic & $351.001^{* * *}$ & $6.200^{* * *}$ \\
\hline (p-value) & $(0.0000)$ & $(0.0000)$ \\
\hline RMALA & Engle LM test & Tsay F test \\
\hline Statistic & $580.955^{* * *}$ & $19.605^{* * *}$ \\
\hline (p-value) & $(0.0000)$ & $(0.0000)$ \\
\hline
\end{tabular}

Notes : ${ }^{* * *}$ denote significance at the level $1 \%$.

\section{Proposed model}

Based on the Singapore and the U.K. stock markets will affect the return rate volatility of the Thailand and the Malaysian stock markets, and the Singapore and the U.K. stock markets do have the high correlations for the Thailand and the Malaysian stock markets. We follows the idea of self-exciting threshold autoregressive (SETAR) model [7], the idea of double threshold GARCH model [8], and the ideas of the papers of Engle [9] and Tse \& Tusi [10], and uses the positive and negative value of Singapore and U.K. stock returns' volatility rate is as a threshold. After model process selection, in this paper, we may use the bivariate asymmetric GARCH (called AGARCH) model to construct the relationships of the Thailand's and the Malaysian's stock market returns, the $\operatorname{AGARCH}(1,1)$ model is illustrated as follows:

$$
\begin{aligned}
& R_{T H A I_{t}}=\phi_{10}+\sum_{j=1}^{2}\left(\phi_{j 1} R T H A I_{t-j}+\phi_{j 2} R M A L A_{t-j}\right. \\
& \left.+\phi_{j 3} R S I N G_{t-j}+\phi_{j 4} R U K_{t-j}\right)+a_{1, t} \\
& R M A L A_{t}=\varphi_{10}+\sum_{j=1}^{2}\left(\varphi_{j 1} R T H A I_{t-j}+\varphi_{j 2} R M A L A_{t-j}\right. \\
& \left.+\varphi_{j 3} R \operatorname{SING} G_{t-j}+\varphi_{j 4} R U K_{t-j}\right)+a_{2, t}, \\
& h_{11, t}=\sum_{j=1}^{4} u_{j, t-1}\left(\alpha_{j 0}+\alpha_{j 1} a_{1, t-1}^{2}+\alpha_{j 2} a_{2, t-1}^{2}+\beta_{j 1} h_{11, t-1}\right) \text {, } \\
& h_{22, t}=\sum_{j=1}^{4} u_{j, t-1}\left(\alpha_{j 0}^{\prime}+\alpha_{j 1}^{\prime} a_{2, t-1}^{2}+\alpha_{j 2}^{\prime} a_{1, t-1}^{2}+\beta_{j 1}^{\prime} h_{22, t-1}\right) \text {, } \\
& h_{12, t}=\rho_{t} \sqrt{h_{11, t}} \sqrt{h_{22, t}}, \\
& \rho_{t}=\exp \left(q_{t}\right) /\left(\exp \left(q_{t}\right)+1\right) \text {, } \\
& q_{t}=\gamma_{0}+\gamma_{1} \rho_{t-1}+\gamma_{2} a_{1, t-1} a_{2, t-1} / \sqrt{h_{11, t-1} h_{22, t-1}} \text {, } \\
& u_{1, t}=\left\{\begin{array}{ccc}
1 & \text {, if } & R \operatorname{SING} G_{t} \leq 0 ; R U K_{t} \leq 0 \\
0 & \text { if } & \text { others }
\end{array},\right. \\
& u_{2, t}=\left\{\begin{array}{ccc}
1 & \text { if } & \operatorname{RSING}_{t} \leq 0 ; R U K_{t}>0 \\
0 & \text { if } & \text { others }
\end{array},\right. \\
& u_{3, t}=\left\{\begin{array}{ccc}
1 & \text { if } & \operatorname{RSING}_{t}>0 ; R U K_{t} \leq 0 \\
0 & \text { if } & \text { others }
\end{array},\right.
\end{aligned}
$$

$$
u_{4, t}=\left\{\begin{array}{ccc}
1 & \text { if } & \text {RSING}_{t}>0 ; R U K_{t}>0 \\
0 & \text { if } & \text { others }
\end{array},\right.
$$

with $R_{S I N G_{t}}>0$ and $R U K_{t}>0$ denote good news (positive values), $R \operatorname{SING}_{t} \leq 0$ and $R U K_{t} \leq 0$ denote bad news (negative values). The white noise of $\vec{a}_{t}^{\prime}=\left(a_{1, t}, a_{2, t}\right)$ is obey the bivariate Student's $t$ distribution, this is,

$$
\vec{a}_{t} \sim T_{v}\left(\overrightarrow{0},(v-2) H_{t} / v\right),
$$

among $\overrightarrow{0}^{\prime}=(0,0)$ and $H_{t}$ is the covariance matrix of $\vec{a}_{t}^{\prime}=\left(a_{1, t}, a_{2, t}\right)$, and $\rho_{t}$ is the dynamic conditional correlation coefficient of $a_{1, t}$ and $a_{2, t}$. The maximum likelihood algorithm method of BHHH [11] is used to estimate the model's unknown parameters. The programs of RATS and EVIEWS are used in this paper.

\section{Empirical results}

From the empirical results, we know that the Thailand's and the Malaysian's stock return volatility may be constructed on the DCC and the bivariate AIGARCH $(1,1)$ model. Its estimate result is stated in Table 6.

The empirical results show that the good news and bad news of the Singapore and the U.K. stock returns' volatility will produce the different stock return rates on the Thailand and the Malaysian stock markets. And the stock return volatilities of the Singapore and the U.K affects the return rate of the Thailand and the Malaysian stock markets. The Thailand stock return volatility does not receive before 2 period's impact of the Thailand stock return volatility. The Thailand stock return does not receive before 2 period's impact of the Malaysian stock return volatility. The Thailand stock return volatility also receives before 1 period's impact of the Singapore stock return volatility $\left(\phi_{13}=-0.064\right)$. The Thailand stock return volatility also receives before 1 period's impact of the U.K. stock return volatility $\left(\phi_{14}=0.190\right)$. The Thailand stock return volatility also receives before 2 period's impact of the U.K. stock return volatility $\left(\phi_{24}=0.047\right)$. The Malaysian stock return volatility does not receive before 2 period's impact of the Thailand stock return volatility. And the Malaysian stock return volatility does not receive before 2 period's impact of the Malaysian stock return volatility. The Malaysian stock return volatility does not receive before 2 period's impact of the Singapore stock return volatility. The Malaysian stock return volatility also receives before 1 period's impact of the U.K. stock return volatility $\left(\varphi_{14}=0.144\right)$. The Malaysian stock return volatility does not receive before 2 nd period's impact of the U.K. stock return volatility. The stock return rate volatilities of the Singapore and the U.K. are also truly 
influent the return volatility of the Thailand and the Malaysian stock markets.

On the other hand, the correlation coefficient average estimation value ( $\hat{\bar{\rho}}_{t}=0.424$ ) of the Thailand and the Malaysian stock return volatility is significant. This result also shows the Thailand and the Malaysian stock return's volatility is mutually synchronized influence. In additional, estimated value of the degree of freedom for the Student's $\mathrm{t}$ distribution is 5.378, and is significant under the significance level of $0.01(\alpha=1 \%)$. This also demonstrates that this research data has the heavy tailed distribution.

Table 6. Parameter estimation of the DCC and the bivariate $\operatorname{AIGARCH}(1,1)$ model

\begin{tabular}{|cccccc|}
\hline Parameters & $\phi_{10}$ & $\phi_{11}$ & $\phi_{12}$ & $\phi_{13}$ & $\phi_{14}$ \\
\hline Coefficient & 0.093 & 0.032 & -0.017 & -0.064 & 0.190 \\
\hline (p-value) & $(0.000)$ & $(0.222)$ & $(0.665)$ & $(0.038)$ & $(0.000)$ \\
\hline Parameters & $\phi_{21}$ & $\phi_{22}$ & $\phi_{23}$ & $\phi_{24}$ & $\varphi_{10}$ \\
\hline Coefficient & 0.027 & 0.002 & -0.011 & 0.047 & 0.045 \\
\hline (p-value) & $(0.300)$ & $(0.954)$ & $(0.719)$ & $(0.081)$ & $(0.001)$ \\
\hline Parameters & $\varphi_{11}$ & $\varphi_{12}$ & $\varphi_{13}$ & $\varphi_{14}$ & $\varphi_{21}$ \\
\hline Coefficient & 0.013 & 0.012 & 0.023 & 0.144 & 0.011 \\
\hline (p-value) & $(0.285)$ & $(0.649)$ & $(0.152)$ & $(0.000)$ & $(0.369)$ \\
\hline Parameters & $\varphi_{22}$ & $\varphi_{23}$ & $\varphi_{24}$ & $\alpha_{10}$ & $\alpha_{11}$ \\
\hline Coefficient & 0.026 & -0.016 & -0.007 & 0.139 & 0.155 \\
\hline (p-value) & $(0.300)$ & $(0.340)$ & $(0.667)$ & $(0.033)$ & $(0.000)$ \\
\hline \hline Parameters & $\alpha_{12}$ & $\beta_{11}$ & $\alpha_{20}$ & $\alpha_{21}$ & $\alpha_{22}$ \\
\hline Coefficient & -0.005 & 0.850 & 0.052 & 0.121 & -0.098 \\
\hline (p-value) & $(0.783)$ & $(0.000)$ & $(0.648)$ & $(0.079)$ & $(0.890)$ \\
\hline Parameters & $\beta_{21}$ & $\alpha_{30}$ & $\alpha_{31}$ & $\alpha_{32}$ & $\beta_{31}$ \\
\hline Coefficient & 0.976 & 0.198 & 0.094 & 0.226 & 0.680 \\
\hline (p-value) & $(0.000)$ & $(0.039)$ & $(0.048)$ & $(0.002)$ & $(0.000)$ \\
\hline Parameters & $\alpha_{40}$ & $\alpha_{41}$ & $\alpha_{42}$ & $\beta_{41}$ & $\alpha_{10}^{\prime}$ \\
\hline Coefficient & 0.008 & 0.114 & 0.029 & 0.856 & 0.040 \\
\hline (p-value) & $(0.881)$ & $(0.001)$ & $(0.462)$ & $(0.000)$ & $(0.005)$ \\
\hline Parameters & $\alpha_{11}^{\prime}$ & $\alpha_{12}^{\prime}$ & $\beta_{11}^{\prime}$ & $\alpha_{20}^{\prime}$ & $\alpha_{21}^{\prime}$ \\
\hline Coefficient & 0.115 & 0.00001 & 0.895 & 0.009 & 0.148 \\
\hline (p-value) & $(0.000)$ & $(0.999)$ & $(0.000)$ & $(0.654)$ & $(0.001)$ \\
\hline Parameters & $\alpha_{22}^{\prime}$ & $\beta_{21}^{\prime}$ & $\alpha_{30}^{\prime}$ & $\alpha_{31}^{\prime}$ & $\alpha_{32}^{\prime}$ \\
\hline Coefficient & -0.010 & 0.862 & -0.0002 & 0.218 & 0.001 \\
\hline (p-value) & $(0.307)$ & $(0.000)$ & $(0.990)$ & $(0.000)$ & $(0.937)$ \\
\hline
\end{tabular}

\begin{tabular}{|cccccc|}
\hline Parameters & $\beta_{31}^{\prime}$ & $\alpha_{40}^{\prime}$ & $\alpha_{41}^{\prime}$ & $\alpha_{42}^{\prime}$ & $\beta_{41}^{\prime}$ \\
\hline Coefficient & 0.782 & 0.008 & 0.094 & 0.002 & 0.904 \\
\hline (p-value) & $(0.000)$ & $(0.455)$ & $(0.000)$ & $(0.606)$ & $(0.000)$ \\
\hline Parameters & $\gamma_{0}$ & $\gamma_{1}$ & $\gamma_{2}$ & $\bar{\rho}_{t}$ & $v$ \\
\hline Coefficient & -1.898 & 3.623 & 0.138 & 0.424 & 5.378 \\
\hline (p-value) & $(0.000)$ & $(0.000)$ & $(0.000)$ & $(0.000)$ & $(0.000)$ \\
\hline Parameters & $\min \rho_{t}$ & $\max \rho_{t}$ & & & \\
\hline Coefficient & 0.1453 & 0.9915 & & & \\
\hline (p-value) & & & & & \\
\hline
\end{tabular}

Notes : p-value $<\alpha$ denotes significance. ( $\alpha=1 \%, \alpha=5 \%)$.

$\min \rho_{t}$ denotes the minimum $\rho_{t}$ and $\max \rho_{t}$ denotes the $\operatorname{maximum} \rho_{t}$.

From the Table 6, the estimated coefficients of the conditional variance equation will produce the different variation risks under the bad news and good news in Thailand and Malaysian stock markets. The empirical results show that the Thailand stock market conforms the conditionally supposition of the AIGARCH model. The empirical results also show that the Malaysian stock market is also the AIGARCH model. This result also demonstrates the DCC and the bivariate $\operatorname{AIGARCH}(1,1)$ model may catch the Thailand and the Malaysian stock return volatilities' process. The empirical result shows that the Thailand stock market has the fixed variation risk, and the Malaysian stock market has also a fixed variation risk. In Table 6, the Thailand and the Malaysian stock market return rates have the different conditional variation risks. This result demonstrates that the good news and bad news of the Singapore and the U.K. stock markets will produce the different variation risks on the Thailand and the Malaysian stock markets. Under the good news of Singapore and U.K. stock markets, the variation risk of the Malaysian's stock market is larger than the variation risk of Thailand's stock market. Under the $R \operatorname{SING} G_{t}>0$ and $R U K_{t} \leq 0$, the empirical result shows that the error square item of Malaysian stock market affects the variation risk of the Thailand stock market. The error square item of Thailand stock market does not influence the variation risk of the Malaysian stock market. Therefore, the explanatory ability of the DCC and the bivariate $\operatorname{AIGARCH}(1,1)$ model is better than the traditional model of the bivariate $\operatorname{IGARCH}(1,1)$.

To test the inappropriateness of the DCC and the bivariate $\operatorname{AIGARCH}(1,1)$ model, the test method of Ljung \& Box [12] is used to examine autocorrelation of the standard residual error. This model does not show an autocorrelation of the standard residual error. Therefore, the DCC and the bivariate $\operatorname{AIGARCH}(1,1)$ model are more appropriate. 


\section{Asymmetric test of the bivariate $\operatorname{AIGARCH}(1,1)$ Model}

The bivariate AIGARCH $(1,1)$ model is proposed as above. The asymmetric test methods [6] are used the following two methods as: positive size bias test and joint test.

By the positive size bias test and the joint test shows that the Thailand stock market does not have the asymmetrical effect and the Malaysian stock market does not also have the asymmetrical effect in Table 7.

Table 7. Asymmetric test of the DCC and the bivariate-AIGARCH $(1,1)$

\begin{tabular}{|c|c|c|}
\hline RTHAI & Positive size bias test & Joint test \\
\hline F statistic & 0.085 & 0.348 \\
\hline (p-value) & $(0.771)$ & $(0.791)$ \\
\hline RMALA & Positive size bias test & Joint test \\
\hline F statistic & 0.085 & 0.207 \\
\hline (p-value) & $(0.771)$ & $(0.892)$ \\
\hline
\end{tabular}

Notes: p-value $<\alpha$ denote significance. $(\alpha=5 \%)$.

\section{Conclusions}

The empirical results show that the return volatilities of the Thailand and the Malaysian stock markets do have an asymmetric effect. The Thailand and the Malaysian stock market return volatility may construct in the DCC and the bivariate AIGARCH $(1,1)$ model with a positive and negative threshold of Singapore and U.K. stock return volatility. From the empirical result also obtains that the DCC coefficients' average estimation value ( $\left.\hat{\bar{\rho}}_{t}=0.424\right)$ of the Thailand and the Malaysian stock return volatility is positive. The positive and negative values of the Singapore and the U.K. stock return volatility affects the stock return volatilities of the Thailand and the Malaysian stock market. The Thailand and the Malaysian stock market return volatilities are truly received the impact of the Singapore and the U.K. stock return volatility. Besides, under the $R S I N G_{t}>0$ and $R U K_{t} \leq 0$, the empirical result shows that the error square item of Malaysian stock market affects the variation risk of the Thailand stock market. The error square item of Thailand stock market does not influence the variation risk of the Malaysian stock market. Therefore, the explanation ability of the bivariate $\operatorname{AIGARCH}(1,1)$ is better than the traditional model of bivariate IGARCH (1, $1)$.

\section{References}

[1] G. Kapetanios, Y. Shin, and A. Snell, "Testing for a unit root in the nonlinear STAR framewo rk," Journal of Econometrics, 112(2), pp. 359-379,2003..

[2] S. Johansen, "Estimation and Hypothesis Testing of Cointegration Vector in Gaussian Vector Autoregressive Models," Econometrica, 52, pp.389402, 1991.
[3] R. F. Engle, "Autoregressive conditional heteroskedasticity with estimates of the variance of United Kingdom Inflation," Econometrica, 50, pp. 987-1007, 1982.

[4] R. S. Tsay, Analysis of Financial Time Series, New York: John Wiley \& Sons, Inc, 2004.

[5] H. Akaike, "Information theory and an extension of the maximum likelihood principle," In 2nd. International Symposium on Information Theory, edited by B. N. Petrov and F. C. Budapest: Akademiai Kiado, pp. 267-281, 1973.

[6] R. F. Engle, and V. K. Ng, "Measuring and testing the impact of news on volatility," Journal of Finance, 48(5), pp. 1749-1777, 1993.

[7] R. S., Tsay, "Testing, and modeling threshold autoregressive processes," Journal of the American Statistical Association, 84, pp. 231-240, 1989.

[8] C. Brooks, "A double-threshold GARCH model for the French Franc / Deutschmark exchange rate," Journal of Forecasting, 20, pp.135-143, 2001.

[9] R. F. Engle, "Dynamic conditional correlation- a simple class of multivariate GARCH models," Journal of Business and Economic Statistics, 20, pp. 339-350, 2002.

[10] Y. K. Tse, and Albert K. C. Tsui, "A multivariate GARCH model with time-varying correlations," Journal of Business \& Economic Statistics, 20, pp. 351-362, 2002.

[11] E. K. Berndt, B. H. Hall, R. E. Hall, and J. A. Hausman, "Estimation and inference in nonlinear structural models," Annals of Economic and Social Measurement, 4, pp. 653-665, 1974.

[12] G. M. Ljung, and G. E. P. Box, "On a measure of lack of fit in time series models," Biometrika, 65(2), pp. 297-303, 1978. 